\title{
p75NTR Regulates Morphine-induced CPP and Related mRNA Expression in Adolescent Mice through Trk Dependent Pathway
}

\section{Qian Zhang}

Henan Provincial People's Hospital

Jiaqi Li

Harbin Medical University

Dong Wu

Henan Provincial People's Hospital

Xiulei Zhang

Henan Provincial People's Hospital

\section{Hai Xiao}

Henan Provincial People's Hospital

\section{Yuwei Zhang}

Henan Provincial People's Hospital

Litao Qin

Henan Provincial People's Hospital

Shixiu Liao ( $\nabla$ yichuansuolsx@126.com )

Henan Provincial People's Hospital https://orcid.org/0000-0003-3126-0027

\section{Research Article}

Keywords: p75NTR, Morphine, Adolescents, CPP

Posted Date: February 16th, 2022

DOI: https://doi.org/10.21203/rs.3.rs-1344543/v1

License: (1) (1) This work is licensed under a Creative Commons Attribution 4.0 International License. Read Full License 


\section{Abstract}

Drug abuses in adolescents have become a major public health concern, and one of the major abusive drugs is morphine. p75NTR is an age-related receptor that can mediate synaptic plasticity in the hippocampus. Previous studies also show that its signaling pathway is involved in some drug-taking behaviors. Using morphine-induced conditioned place preference (CPP) of mice, the present study aims to analyze changes of p75NTR in the hippocampus. As the expression and function of p75NTR can be regulated by the activities of Trk receptors, we also aim to detect whether the activation of Trk can regulate changes in expressions of p75NTR and acquisitions of morphine-induced CPP. Our results show that the expression of p75NTR in the hippocampus is significantly increased in the morphine-induced CPP of adolescent mice, but not in that of adult mice. It can be explained by that the p75NTR plays a more important role in the brains of adolescent mice. We also find a Trk phosphorylation inhibitor, K252a, can reduce the preference values of CPP in adolescent mice, as well as attenuating the mRNA expression of p75NTR and its downstream molecular, CDC42, in the hippocampus of adolescent mice. The present study suggests that the p75NTR may be an age-related regulator of morphine abuse, and its function may be regulated by the activity of Trk.

\section{Highlights}

1. p75NTR was found highly expressed in the hippocampus of adolescent mice but not adult mice.

2. K252a could significantly inhibited the CPP and p75NTR-expression of adolescent mice

3. K252a had no significant effect on adult mice.

\section{Introduction}

According to the "World Drug Report 2020", the proportion of adolescents and young adults with drug addicts was growing steadily, and has accounted for the largest population in 2020 (UNODC, 2020). In recent years, opioid abuse has become the form of drug misuse and abuse. Morphine is an opioid analgesic and used clinically to treat severe pain. Long-term abuse of morphine can cause physical and psychological dependence. More seriously, people who abuse morphine tend to relapse even after years of sobriety (Listos $\mathrm{J}$ et al., 2019). Adolescence is typified as a critical stage of brain in synaptic developing and neuronal connectivity (Fuhrmann D et al., 2015;Mengler $L$ et al., 2014), as adolescents are more sensitive to opioid (Montiel Ishino FA et al., 2020) (Salas-Wright CP et al., 2018) (Stanley LR et al., 2021). Therefore, adolescent morphine abuse has become a major public health concern.

p75 neurotrophin receptor ( $p 75$ NTR) is a member of neurotrophic receptors family that involved in neuron survival and death. Also, p75NTR can mediate synaptic plasticity and age-related changes in hippocampus (Wong LW et al., 2021). Recent studies revealed a significant correlation between p75NTR and drug abuse (Cadet JL et al., 2019;Torres OV et al., 2018). A study about alcohol intake showed that knockdown of p75NTR expression significantly reduced excessive alcohol intake among rats (Darcq E et 
al., 2016). Researchers have also found evidence that the striatal p75NTR signaling pathway was involved in methamphetamine-taking behaviors (Cadet JL,Patel R and Jayanthi S, 2019;Torres OV,Jayanthi S,McCoy MT and Cadet JL, 2018). But it is unknown whether p75NTR plays a role in morphine misuses and abuses.

The function of p75NTR are determined not only by the expressed cellular components, but also by its receptor complex and ligands. It forms a complex with tropomyosin-related kinase (Trk) receptors, which increases the affinity for the mature neurotrophin ligands (Bibel M et al., 1999;Hempstead BL et al., 1991;Zanin JP et al., 2019). The autophosphorylation of TrkA regulates p75NTR expression (Rankin SL et al., 2005). Cleavage of p75NTR requires TrkA activation, rather than ligand binding to p75NTR (Ceni $C$ et al., 2010).

The purpose of the present study is to investigate the expression change of p75NTR in hippocampus in morphine-induced conditioning place preference (CPP) of mice, and whether the expression of p75NTR in morphine-induced CPP of mice is associated with TrkA activation. The CPP is commonly used to measure the underlying mechanisms of drug seeking behavior, drug-induced reinstatement, and drug associated learning and memories (Prus AJ et al., 2009). Especially when mice entering into the relevant environment, repeated exposure of morphine result the formation of addictive memory and the symptoms of drug seeking behavior. Using the computational video-tracking technology, we established the morphine-induced mice CPP acquisition, extinction and reinstatement model. In the present study, using K252a (a Trk tyrosine kinase inhibitor), we examine the mRNA levels of relevant genes primarily in successfully morphine-induced CPP of mice models with quantitative real time PCR (qRT-PCR), and analyze the changes of expressions in P75NTR and its relevant signaling pathways, to explore the relationship between the expression of p75NTR and morphine abuse.

\section{Materials And Methods}

\section{Animals}

Male C57BL/6 mice (Animal Center of Xi'an Jiaotong University, Xi'an, China) aging $4(n=48)$ and 8 weeks $(n=42)$ were used in the current study. Animals were housed in groups of four per cage with free access to food and water under controlled laboratory conditions at a constant temperature $\left(23 \pm 2^{\circ} \mathrm{C}\right)$ and humidity $(55 \pm 5 \%)$, and $12 \mathrm{~h}$ light/dark cycles. The mice were acclimated to the laboratory for 7 days before the experiments.

\section{Drugs}

Morphine hydrochloride ( $10 \mathrm{mg} / \mathrm{ml}$, key laboratory of forensic medicine, Xi'an Jiaotong University) was dissolved in $0.9 \%$ physiological saline and to a volume of $2 \mathrm{mg} / \mathrm{ml}$. K252a (Shanghai Weisheng biotechnology co., LTD, Shanghai, China) was dissolved in DSMO to a volume of $0.5 \mathrm{mg} / \mathrm{ml}$. All drugs were administered by intraperitoneal injection (i.p.) and injection standard is $10 \mathrm{mg} / \mathrm{kg}$ according to the mouse weight. 


\section{Conditioned place preference (CPP)}

\subsection{Groups}

CPP experiment was conducted with two parts:

First part: 19 adolescent mice were randomly divided into SAL group (saline, i.p., $n=9$ ) and MOR group $(2 \mathrm{mg} / \mathrm{ml}$ morphine, i.p., $\mathrm{n}=10$ ); 12 adult mice were randomly divided into SAL group (saline, i.p., $\mathrm{n}=6$ ) and MOR group ( $2 \mathrm{mg} / \mathrm{ml}$ morphine, i.p., $\mathrm{n}=6)$.

Second part: 39 adolescent mice were randomly divided into 4 groups: CS group (10\% DMSO + saline, i.p.,n = 9), CM group (10\% DMSO + morphine, i.p.,n = 9), KS group $(0.5 \mathrm{mg} / \mathrm{ml} \mathrm{K252a}+$ saline, i.p., $\mathrm{n}=9), \mathrm{KM}$ group $(0.5 \mathrm{mg} / \mathrm{ml} \mathrm{k252a}+$ morphine, i.p., $\mathrm{n}=10) ; 30$ adult mice were randomly divided into 4 groups $\square \mathrm{CS}$ group (10\% DMSO + saline, i.p., $\mathrm{n}=8), \mathrm{CM}$ group $(10 \% \mathrm{DMSO}+$ morphine, i.p., $\mathrm{n}=7), \mathrm{KS}$ group $(0.5 \mathrm{mg} / \mathrm{ml}$ $\mathrm{K} 252 \mathrm{a}+$ saline, i.p., $\mathrm{n}=9), \mathrm{KM}$ group $(0.5 \mathrm{mg} / \mathrm{ml} \mathrm{k} 252 \mathrm{a}+$ morphine, i.p., $\mathrm{n}=6)$.

The interval between the two administrations was 15 minutes.

\subsection{Behavioral apparatus}

The CPP apparatus (JLBeHv, Shanghai, China) comprised two chambers $(30 \times 16 \times 35 \mathrm{~cm})$, connected by a door that could be closed or open when required. The two chambers contained distinctive tactile and visual features. The left chamber of the apparatus had a black background with a grid floor (giving saline), and the right chamber had a white background with a mesh floor (giving morphine). The entire apparatus was enclosed in a ventilated recording cabinet. The mice' behavior was monitored with camera mounted at the top of apparatus, and DigBehv software (JLBeHv, Shanghai, China) was used for the capture and analysis of activity.

\subsection{Procedure of CPP}

The experiment had three phases: pre-test, training, and post-test. The experimental process is shown in the Fig. 1:

\section{Pre-test}

On day 1 , we opened the door and put the mice into the equipment from right chamber without any treatment. The mice could explore both chambers of the apparatus with the door open for $15 \mathrm{mins}$. Mice that stayed in any chamber longer than 600 s or shuttled less than 20 times were removed.

\section{Training}

On day 2, each mouse was confined to the left chamber (with a black background and a grid floor) for $45 \mathrm{~min}$ immediately following saline injection and the right chamber (a white background with a mesh 
floor) following morphine injection the next day (day 3). This has been repeated for 8 days, with saline and morphine injections administered on alternating days.

\section{Post-test}

On day 10 , the mice were allowed to explore both chambers of the apparatus with the door open freely for 15 mins without any injection.

\section{Preference score}

The preference score is equal to the time that mice stay in the left chamber(saline injection)minus the time that mice stay in the right chamber (morphine injection)

\section{RNA extraction and Quantitative real time PCR (qRT-PCR)}

\subsection{RNA extraction and reverse transcription}

The mice were sacrificed $1 \mathrm{~h}$ later after the post-test phase. The brain tissue were taken out and the hippocampus of mice were isolated and frozen at $-80^{\circ} \mathrm{C}$ until use. Total RNA was extracted from the mice' hippocampus by using the Mini BEST Universal RNA Extraction Kit (TaKaRa, Japan). The RNA concentration and quality were determined with a Nano Drop spectrophotometer (Thermo Scientific, USA). Then, $500 \mathrm{ng}$ of total RNA were reversely transcribed into $10 \mu \mathrm{l}$ of cDNAs with the PrimeScript® RT Reagents Kit (Perfect Real Time) (TaKaRa, Japan) via using the following parameters: $37^{\circ} \mathrm{C}$ for $15 \mathrm{~min}$, $85^{\circ} \mathrm{C}$ for $5 \mathrm{~s}$, and $4^{\circ} \mathrm{C}$ for $5 \mathrm{~min}$.

\section{2 qRT-PCR}

The cDNAs from each sample were used for qRT-PCR with the SYBR® Premix Ex Taq II Mix (TaKaRa, Japan). Using a Bio-Rad iQ5 detection instrument (Bio-Rad, USA) qRT-PCR was performed with the following conditions: $95^{\circ} \mathrm{C}$ for $30 \mathrm{~s}, 40$ cycles of $95^{\circ} \mathrm{C}$ for $5 \mathrm{~s}$ and $65^{\circ} \mathrm{C}$ for $20 \mathrm{~s}$. Tbp was chosen and used as an endogenous control for qRT-PCR (Zhang Q et al., 2018). The relative expression levels were determined with the $2^{-\Delta \Delta C t}$ method. The sequences of the primer pairs are shown in Table 1.

\section{Statistical analysis}

The experimental data were analyzed by IBM SPSS Statistics 13.0 software. The results were shown by mean \pm SEM, and $P<0.05$ was considered statistically significant.

For the behavioral test, the dependent variable was preference score. Mixed ANOVA was used to analyze for the pre-test and post-test of CPP, with days (pre-test and post-test) as within-subject variable and treatments (K252a and morphine) as between-subject factor. Main and interaction levels were significant at $P<0.05$. 
Using a Bio-Rad iQ5 detection instrument (Bio-Rad, USA) to determine CT values. Each sample was tested three times. They were calculated with the $2-\Delta \Delta \mathrm{Ct}$ method. The CS group and CM groups were analyzed by t-test, and the DS group and DM group are analyzed with two way ANOVA.

\section{Results}

\section{1. p75NTR is upregulated in the hippocampus of adolescent morphine-induced CCP mice}

First we detected the mRNA expression of p75NTR in adolescent and adult morphine-induced CPP mice (the procedure was showed in Fig. 1A). Morphine-induced CPP affected p75NTR expression in both adolescent mice (Fig. 1B, ${ }^{\#} P<0.01$, Mixed measured ANOVA, morphine: $F_{1,17}=13.713, P<0.05$, and day: $F_{1,17}=14.271, P<0.05$, as well as the interaction of morphine $\times$ day: $\left.F_{1,17}=13.713, P<0.05\right)$ and adult mice (Fig. 1C, Mixed measured ANOVA, morphine: $F_{1,11}=6.192, P<0.05$, and day: $F_{1,11}=6.828, P<0.05$, as well as the interaction of morphine $\times$ day: $\left.F_{1,11}=11.435, P<0.05\right)$.

In the experiment, we used the different time-span that mice spent in the morphine-associated chamber versus saline-associated chamber as the measure of place preference (preference score). All mice showed no significant differences in the preference score on the pre-test day. The treatment with $10 \mathrm{mg} / \mathrm{kg}$ morphine significantly increased the preference score in both adolescent (Fig. 1B, ${ }^{\star \star} P<0.01$ ) and adult mice (Fig. 1C, ${ }^{* *} P<0.01$ ), when comparing with their controlled saline-groups respectively. The morphine treatment also induced CPP in both adolescent mice (Fig. 1B, ${ }^{\# \#} P<0.01$ ) and adult mice (Fig. 1C, ${ }^{\# \#} P<0.01$ ).

We detected the p75NTR expression in the hoppocampus one hour after the post-test. The result showed that the expression of p75NTR in the hippocampus of the morphine group was significantly increased in the adolescent mice rather than adult mice ( ${ }^{\star \star} P<0.01$, Fig. 1D and $\left.1 \mathrm{E}\right)$.

\section{TrkA inhibitor K252a affected the expression of p75NTR and morphine-induced CPP of adolescent mice}

p75NTR is expressed at low levels as sympathetic axons project toward their targets, which enables neurotrophin-3 (NT3) to activate TrkA receptors and promote growth. Upon reaching nerve growth factor (NGF) producing tissues, p75NTR is upregulated, resulting in the formation of TrkA-p75 complexes, highaffinity binding sites selective for NGF, thereby blunting NT3 signaling. To further investigate the effect of p75NTR on morphine-induced CPP in mice, we used a Trk inhibitor K252a to antagonize the activities of TrkA-p75 complexes and block the function of p75NTR. Then we detected CPP and the expression of p75NTR in the hippocampus of mice (Fig. 2A, Mixed measured ANOVA revealed main effects of K252a $\left(F_{1,25}=0.683, P>0.05\right)$, morphine $\left(F_{1,25}=4.067, P>0.05\right)$ and day $\left(F_{1,25}=11.524, P<0.05\right)$, as well as the interaction of K252ax morphine $\left(F_{1,25}=0.084, P>0.05\right), K 252 a \times$ day $\left(F_{1,25}=1.81, P>0.05\right)$, morphine $\times$ day $\left(\mathrm{F}_{1,25}=11.57, P<0.05\right), \mathrm{K} 252 \mathrm{a} \times$ morphine $\times$ day $\left.\left(\mathrm{F}_{1,25}=5.294, P<0.05\right)\right)$. 
The results showed that CPP was formed in both DM and KM group (Fig. $2 \mathrm{~A},{ }^{*} P<0.05, \star \star P<0.01$ ). Both groups also showed higher preference score compared with DS and KS group respectively (Fig. 3A, ${ }^{\#} P<$ 0.05 , $\left.{ }^{\# \#} P<0.01\right)$. However, the preference score of CPP in KM group was significantly lower than that in the DM group, suggesting that K252a could inhabit the expression of $\mathrm{CPP}\left({ }^{+} P<0.05\right)$.

We used qRT-PCR to test the mRNA expression of p75NTR and its target CDC42. Our research showed that p75NTR was significantly increased in the DM group than in the DS group ( $\left.{ }^{*} P<0.05\right)$. However, when the adolescent mice were treated with K252a, the mRNA expression of p75NTR in the was significantly decreased in the KM group than in the DM group ( $\left.{ }^{\#} P<0.05\right)$. Moreover, there was no significant difference of p75NTR compared with the KS group (Fig. 2B, Two-way ANOVA revealed significant main effects of $\mathrm{K} 252 \mathrm{a}\left(\mathrm{F}_{1,27}=0.710, P>0.05\right)$, morphine $\left(\mathrm{F}_{1,27}=2.352, P>0.05\right)$, and interactions of K252ax morphine $\left.\left(\mathrm{F}_{1,27}=3.912, P>0.05\right).\right)$.

As shown in Fig. 2C, after mice were exposure to morphine,CDC42 levels in the DM group were increased in comparison to the DS group ( ${ }^{*} P<0.05$ ). Meanwhile, when mice were injected with $\mathrm{K} 252 \mathrm{a}$, the mRNA expressions of CDC42 had no significance in the KM group and KS group but significantly decreased in the KM group in comparison to the DM group ( ${ }^{\#} P<0.05$ ) (Fig. 2C, Two-way ANOVA revealed significant main effects of K252a: $F_{1,28}=0.690, P>0.05$, morphine: $F_{1,28}=2.133, P>0.05$ and interaction of K252ax morphine: $\left.\mathrm{F}_{1,28}=7.378, P<0.05\right)$

\section{Effect of K252a on the expression changes of p75NTR and morphine-induced CPP of adult mice}

We investigated the effect of K252a on morphine induced-CPP and K252a-expression in adult mice. On the Fig. $3 \mathrm{~A}$, the preference score in the DM and KM group were higher than that in the DS and KS group respectively ( ${ }^{\#} P<0.05,{ }^{\# \#} P<0.01$ ). The results showed that CPP was formed in both CM and KM group compared with CS and CM group respectively $\left({ }^{\star} P<0.05,{ }^{\star} * P<0.01\right)$. However, there was no significant difference in the preference score in the KM group compared with the CM group, suggesting K252a cannot inhibit CPP expression (Fig. 3A. Mixed measured ANOVA revealed main effects of K252a $\left(\mathrm{F}_{1,26}=\right.$ $2.531, P>0.05)$, morphine $\left(F_{1,26}=13.372, P<0.05\right)$ and day $\left(F_{1,26}=17.07, P<0.05\right)$, as well as the interaction of $\mathrm{K} 252 \mathrm{a} \times$ morphine $\left(\mathrm{F}_{1,26}=0.001, P>0.05\right), \mathrm{K} 252 \mathrm{a} \times$ day $\left(\mathrm{F}_{1,26}=1.093, P>0.05\right)$, morphine $\times$ day $\left(F_{1,26}=21.517, P<0.05\right), \mathrm{K} 252 \mathrm{a} \times$ morphine $\times$ day $\left.\left(\mathrm{F}_{1,26}=0.087, P>0.05\right)\right)$.

For the expression of p75NTR, neither morphine nor K252a could not significantly affect the expression of p75NTR. In the hippocampus of adult mice, the mRNA expression of p75NTR in the CM group and KM showed no significant difference compared with CS group and CM group respectively. There was also no significant difference of p75NTR between the CM group and KM group (Fig. 3B, Two-way ANOVA revealed significant main effects of K252a: $F_{1,25}=0.916, P>0.05$, morphine: $F_{1,25}=13.499, P<0.05$ and interaction of $\mathrm{K} 252 \mathrm{a} \times$ morphine: $\left.\mathrm{F}_{1,25}=0.646, P>0.05\right)$.

Similar to the results of p75NTR, The mRNA's expression of CDC42 and in the CM and KM group had significant difference compared with the CS and KS group respectively, while the mRNA expression of 
CDC42 kept same level in the CM group and KM group (Fig. 3C, Two-way ANOVA revealed significant main effects of K252a: $F_{1,25}=1.646, P>0.05$, morphine: $F_{1,25}=1.646, P>0.05$ and interaction of $K 252 a \times$ morphine: $\left.\mathrm{F}_{1,25}=1.802, P>0.05\right)$.

\section{Discussion}

Adolescence is an important stage of brain development. People who start drug abuse in adolescence are more likely to develop substance use disorders than people who start as adults (Richmond-Rakerd LS et al., 2016) (Corongiu S et al., 2020).

Previous studies has shown that when they enter the relevant environment, they show symptoms of craving for the drug, so repeated morphine use can pair the drug with some environmental cues (McKendrick G et al., 2020). Here we showed that morphine significantly induced CPP in adolescent and adult mice. Morphine-induced mice stayed relatively longer in the drug compartment than the saline treatment groups, which indicated that the mice has developed a form of memory associated environmental cues after repeated morphine treatment. This form of memory, which associates environmental cues with morphine use, plays an important role in the development of morphine abuse and the hippocampus is crucial in storing and releasing memory in this session (Portugal GS et al., 2014).

p75NTR, a receptor for the neurotrophin family of growth factors. It can mediate neuron function, predominantly in maintaining the normal function of the nervous system, such as neuron apoptosis, axon elongation, and synaptic plasticity (Shu YH et al., 2015). Tang et al. found that p75NTR played its part in LTP/LTD-induced synaptic enhancement and inhibition in the hippocampus (Tang JJ et al., 2021). Because some studies confirmed that LTP/LTD-induced synaptic enhancement and inhibition in the hippocampus is closely related to CPP, and even morphine-induced CPP, we suggested that p75NTR may has some function in regulating morphine abuse. In our study, we found that the expression of p75NTR was significantly increased in the hippocampus of adolescent mice, possibly indicating that p75NTR alteration was related to the morphine-induced CPP. The increasing expression of p75NTR may represent the change of synaptic plasticity and new memory development related to drug abuse. Similar to our results, researchers have found that p75NTR plays an important role in neuro function in drug abuse. Knockdown of p75NTR could attenuate excessive alcohol drinking (Darcq E,Morisot N,Phamluong K,Warnault V,Jeanblanc J,Longo FM,Massa SM and Ron D, 2016). p75NTR could affect neuronal apoptosis induced by morphine withdrawal (Asuni GP et al., 2021).

Brain development involves a series of molecular expression changes, such as PTBP2 and PSD-95, that increase in adulthood, while some gradually decrease, such as PTBP1 (Dow-Edwards D et al., 2019). These molecular changes may be associated with some emotional and behavioral differences between adolescence and adulthood, and these differences may be used to diagnose some diseases. Particularly, previous studies have shown that the p75NTR is widely expressed throughout the CNS during the development, but such expressions are attenuated as age grows (Woo NH et al., 2005). One of the changes is the appearance of endogenous levels of proBDNF protein might have an advantage during the 
early postnatal development (0-8 weeks), and this is consistent with a higher level of p75NTR in the hippocampus (Woo NH,Teng HK,Siao CJ,Chiaruttini C,Pang PT,Milner TA,Hempstead BL and Lu B, 2005; Yang $\mathrm{J}$ et al., 2014). These studies have also indicated that p75NTR was involved in proBDNF regulated hippocampal long term depression (LTD) (Sakuragi S et al., 2013;Woo NH,Teng HK,Siao CJ,Chiaruttini C,Pang PT,Milner TA,Hempstead BL and Lu B, 2005). Our study showed similar results. We found that p75NTR was significantly increased in the hippocampus of adolescent mice but not adult mice. This shows that p75NTR may be significantly involved in morphine abuse of adolescent brains because it mainly regulates synaptic plasticity in the hippocampus during brain development. Moreover, our study also shows that adolescents might be more sensitive to positive rewarding properties than adults, such as drugs and natural stimuli(Garofoli M, 2020) (Salmanzadeh $\mathrm{H}$ et al., 2021).

In many cases, the function of p75NTR is determined not only by itself but also by its receptor complex. Studies on NGF binding demonstrated that the high-affinity-binding site is actually generated by a complex of TrkA and p75NTR, and that the presence of p75NTR enhances ligand discrimination as well as binding affinity (Hempstead BL,Martin-Zanca D,Kaplan DR,Parada LF and Chao MV, 1991;Skeldal S et al., 2011). Besides, the activity of Trk receptor has been shown to induce different outcomes of neuron via p75NTR. Also, p75NTR works as an apoptotic receptor independent of Trk as well as a signaling receptor dependent of Trk activation (Kaplan DR and Miller FD, 2000). TrkB-p75NTR signaling cascades could modulate dendritic growth in the hippocampus (Hartmann M et al., 2004). Thus, the regulation of p75NTR on neural plasticity might be related to the activation of Trk.

Researchers have also found that the function of p75NTR might be related to the activation of Trk family in some drug dependence. For example, rats with distinct phenotypes of foot shock for methamphetamine intake display differential changes in an intracellular signaling cascade activated by nerve growth factor TrkA/p75NTR interactions (Torres OV,Jayanthi S,McCoy MT and Cadet JL, 2018). Moreover, TrkA might enhance p75NTR activation and subsequent signaling to play a significant role in cocaine behavioral sensitization (Zhang Y et al., 2015) .

For further analysis on the effect of p75NTR on morphine-induced CPP of mice, we used K252a, a Trk phosphorylation antagonism, to inhibit the activity of Trk and even the function of p75NTR. We found K252a could significantly reduce the expression of p75NTR and the preference values of CPP in adolescent mice. These results showed that the activity of Trk might significantly reduce p75NTR expression. It may also down-regulated morphine-induced CPP of adolescent mice through inhibit p75NTR expression. However, K252a has no significant effect on the CPP in adult mice and the mRNA expression of p75NTR. It is same as our results above. p75NTR mainly affected morphine related memory forming and releasing because it has higher expression and more active role in neuronal function during the brain development (Woo NH,Teng HK,Siao CJ,Chiaruttini C,Pang PT,Milner TA,Hempstead BL and Lu B, 2005;Yang J,Harte-Hargrove LC,Siao CJ,Marinic T,Clarke R,Ma Q,Jing D,Lafrancois JJ,Bath KG,Mark W,Ballon D,Lee FS,Scharfman HE and Hempstead BL, 2014). All these results suggested that p75NTR may be related with morphine-induced CPP. It is critical to morphine 
preference in developing brains rather than developed brains. Moreover, this effect of p75NTR in adolescent mice may be closely associated with Trk activation.

CDC42 is the downstream target of p75NTR. It was shown to be involved in some neuron functions in the brain (Chen $\mathrm{C}$ et al., 2012). In our study, we found K252a could attenuate the mRNA expression of CDC42 in the hippocampus of adolescent mice but not in that of adult mice in morphine-induced CPP. It is indicated that the inhibition of TrkA may affect p75NTR related signal pathway during development of brain. We showed the mRNA expression changes of P75NTR and CDC42 were consistent with the change of CPP, and that it is suggested that p75NTR and CDC42 signal pathway may be involved in morphine preference in adolescent mice. And the regulating effect p75NTR and CDC42 signal pathway may be affect by TrkA activation.

Based on this evidence, our studies showed that the Trk-dependent activity of p75NTR might be involved in morphine-induced CPP in adolescent mice. Furthermore, these studies showed the differential changes of p75NTR in the hippocampus of morphine-treated adolescent mice. It suggested that the p75NTR may be an age-related regulator of morphine abuse. Besides, dysregulating the expression of p75NTR by the activity of Trk-p75NTR could affect morphine abuse behavior in adolescent mice.

\section{Conclusions}

Morphine could induce CPP in both adolescent mice and adult mice. In the present study, p75NTR and its downstream molecule CDC42 were identified as significantly increased in the hippocampus of adolescent mice but not adult mice. Compared to adult mice, the preference of CPP could be substantially inhibited by K252a. Impotently, in the hippocampus, K252a could also reduce the expression of p75NTR and CDC42 of adolescent mice but not significantly affect their expression in adult mice.

\section{Declarations}

Acknowledgements The authors would like to give thanks to Linya Jin for assisting with data collecting, as well as Qianhui Ma and Mengyang Zhang for writing revision.

Authors' Contributions Study concept and design: Qian Zhang, Jiaqi Li and Shixiu Liao; experimental operation: Qian Zhang, Jiaqi Li, Dong Wu and Xiulei Zhang; acquisition, analysis and interpretation of data: Qian Zhang, Jiaqi Li, Hai Xiao and Yuwei Zhang; manuscript drafting: Qian Zhang, Jiaqi Li and Litao Qin; supervision, Shixiu Liao and Litao Qin; funding acquisition, Qian Zhang, Jiaqi Li, Dong Wu and Litao Qin.

Availability of data and materials Behavioral data, molecular data, drug, animal and device informations Conflict of Interest The authors declare that they have no confict of interest.

Consent for publication All the authors agreed to publish the study. 
Ethics Approval The study was approved by the ethics committees of Harbin Medical University (Harbin, China)

Funding This study was funded by the Council of National Natural Science Foundation of China (NFSC 81801549), 2019 Basic scientific research projects of Heilongjiang Provincial Colleges and Universities (31041190056), Science and Technology Development Program of Henan (182102310503) and Medical science and Technology research project of Henan Province (LHGJ20210051).

Data Availability Statement The datasets generated during and/or analysed during the current study are available from the corresponding author on reasonable request.

\section{References}

1. Asuni GP, Speidell A, Mocchetti I (2021) Neuronal apoptosis induced by morphine withdrawal is mediated by the $\mathrm{p} 75$ neurotrophin receptor. $\mathrm{J}$ Neurochem

2. Bibel M, Hoppe E, Barde YA (1999) Biochemical and functional interactions between the neurotrophin receptors trk and p75NTR. Embo j 18:616-622

3. Cadet JL, Patel R, Jayanthi S (2019) Compulsive methamphetamine taking and abstinence in the presence of adverse consequences: Epigenetic and transcriptional consequences in the rat brain. Pharmacol Biochem Behav 179:98-108

4. Ceni C, Kommaddi RP, Thomas R, Vereker E, Liu X, McPherson PS, Ritter B, Barker PA (2010) The p75NTR intracellular domain generated by neurotrophin-induced receptor cleavage potentiates Trk signaling. J Cell Sci 123:2299-2307

5. Chen C, Wirth A, Ponimaskin E (2012) Cdc42: an important regulator of neuronal morphology. Int J Biochem Cell Biol 44:447-451

6. Corongiu S, Dessi C, Cadoni C (2020) Adolescence versus adulthood: Differences in basal mesolimbic and nigrostriatal dopamine transmission and response to drugs of abuse. Addict Biol 25:e12721

7. Darcq E, Morisot N, Phamluong K, Warnault V, Jeanblanc J, Longo FM, Massa SM, Ron D (2016) The Neurotrophic Factor Receptor p75 in the Rat Dorsolateral Striatum Drives Excessive Alcohol Drinking. J Neurosci 36:10116-10127

8. Dow-Edwards D, MacMaster FP, Peterson BS, Niesink R, Andersen S, Braams BR (2019) Experience during adolescence shapes brain development: From synapses and networks to normal and pathological behavior. Neurotoxicol Teratol 76:106834

9. Fuhrmann D, Knoll LJ, Blakemore SJ (2015) Adolescence as a Sensitive Period of Brain Development. Trends Cogn Sci 19:558-566

10. Garofoli M (2020) Adolescent Substance Abuse. Prim Care 47:383-394

11. Hartmann M, Brigadski T, Erdmann KS, Holtmann B, Sendtner M, Narz F, Lessmann V (2004) Truncated TrkB receptor-induced outgrowth of dendritic filopodia involves the p75 neurotrophin 
receptor. J Cell Sci 117:5803-5814

12. Hempstead BL, Martin-Zanca D, Kaplan DR, Parada LF, Chao MV (1991) High-affinity NGF binding requires coexpression of the trk proto-oncogene and the low-affinity NGF receptor. Nature 350:678683

13. Kaplan DR, Miller FD (2000) Neurotrophin signal transduction in the nervous system. Curr Opin Neurobiol 10:381-391

14. Listos J, Lupina M, Talarek S, Mazur A, Orzelska-Gorka J, Kotlinska J (2019) The Mechanisms Involved in Morphine Addiction: An Overview.Int J Mol Sci20

15. McKendrick G, Garrett H, Jones HE, McDevitt DS, Sharma S, Silberman Y, Graziane NM (2020) Ketamine Blocks Morphine-Induced Conditioned Place Preference and Anxiety-Like Behaviors in Mice. Front Behav Neurosci 14:75

16. Mengler L, Khmelinskii A, Diedenhofen M, Po C, Staring M, Lelieveldt BP, Hoehn M (2014) Brain maturation of the adolescent rat cortex and striatum: changes in volume and myelination. Neurolmage 84:35-44

17. Montiel Ishino FA, Gilreath T, Williams F (2020) Finding the Hidden Risk Profiles of the United States Opioid Epidemic: Using a Person-Centered Approach on a National Dataset of Noninstitutionalized Adults Reporting Opioid Misuse.Int J Environ Res Public Health17

18. Portugal GS, Al-Hasani R, Fakira AK, Gonzalez-Romero JL, Melyan Z, McCall JG, Bruchas MR, Morón JA (2014) Hippocampal long-term potentiation is disrupted during expression and extinction but is restored after reinstatement of morphine place preference. J Neurosci 34:527-538

19. Rankin SL, Guy CS, Mearow KM (2005) TrkA NGF receptor plays a role in the modulation of p75NTR expression. Neurosci Lett 383:305-310

20. Richmond-Rakerd LS, Slutske WS, Lynskey MT, Agrawal A, Madden PA, Bucholz KK, Heath AC, Statham DJ et al (2016) Age at first use and later substance use disorder: Shared genetic and environmental pathways for nicotine, alcohol, and cannabis. J Abnorm Psychol 125:946-959

21. Sakuragi S, Tominaga-Yoshino K, Ogura A (2013) Involvement of TrkB- and p75(NTR)-signaling pathways in two contrasting forms of long-lasting synaptic plasticity. Sci Rep 3:3185

22. Salas-Wright CP, Oh S, Vaughn MG, Muroff J, Amodeo M, Delva J (2018) Trends and correlates of perceived access to heroin among young adults in the United States, 2002-2016. Drug Alcohol Depend 193:169-176

23. Salmanzadeh H, Ahmadi-Soleimani SM, Azadi M, Halliwell RF, Azizi H (2021) Adolescent Substance Abuse, Transgenerational Consequences and Epigenetics. Curr Neuropharmacol 19:1560-1569

24. Shu YH, Lu XM, Wei JX, Xiao L, Wang YT (2015) Update on the role of p75NTR in neurological disorders: A novel therapeutic target. Biomed Pharmacother 76:17-23

25. Skeldal S, Matusica D, Nykjaer A, Coulson EJ (2011) Proteolytic processing of the p75 neurotrophin receptor: A prerequisite for signalling?: Neuronal life, growth and death signalling are crucially regulated by intra-membrane proteolysis and trafficking of p75(NTR). BioEssays 33:614-625 
26. Stanley LR, Crabtree MA, Swaim RC (2021) Opioid Misuse Among American Indian Adolescents. Am J Public Health 111:471-474

27. Tang JJ, Feng S, Chen XD, Huang H, Mao M, Wang HY, Li S, Lu XM et al (2021) The Effects of P75NTR on Learning Memory Mediated by Hippocampal Apoptosis and Synaptic Plasticity. Curr Pharm Des 27:531-539

28. Torres OV, Jayanthi S, McCoy MT, Cadet JL (2018) Selective Activation of Striatal NGFTrkA/p75NTR/MAPK Intracellular Signaling in Rats That Show Suppression of Methamphetamine Intake 30 Days following Drug Abstinence. Int J Neuropsychopharmacol 21:281-290

29. UNODC (2020) 2020 World Drug Report

30. Wong LW, Chong YS, Lin W, Kisiswa L, Sim E, Ibanez CF, Sajikumar S (2021) Age-related changes in hippocampal-dependent synaptic plasticity and memory mediated by p75 neurotrophin receptor. Aging Cell 20:e13305

31. Woo NH, Teng HK, Siao CJ, Chiaruttini C, Pang PT, Milner TA, Hempstead BL, Lu B (2005) Activation of p75NTR by proBDNF facilitates hippocampal long-term depression. Nat Neurosci 8:1069-1077

32. Yang J, Harte-Hargrove LC, Siao CJ, Marinic T, Clarke R, Ma Q, Jing D, Lafrancois JJ et al (2014) proBDNF negatively regulates neuronal remodeling, synaptic transmission, and synaptic plasticity in hippocampus. Cell Rep 7:796-806

33. Zanin JP, Montroull LE, Volosin M, Friedman WJ (2019) The p75 Neurotrophin Receptor Facilitates TrkB Signaling and Function in Rat Hippocampal Neurons. Front Cell Neurosci 13:485

34. Zhang Q, Zhang M, Li J, Xiao H, Wu D, Guo Q, Zhang Y, Wang H et al (2018) Selection and Validation of Reference Genes for RT-PCR Expression Analysis of Candidate Genes Involved in MorphineInduced Conditioned Place Preference Mice. J Mol Neurosci 66:587-594

35. Zhang Y, Zhu X, Huang C, Zhang X (2015) Molecular changes in the medial prefrontal cortex and nucleus accumbens are associated with blocking the behavioral sensitization to cocaine. Sci Rep $5: 16172$

\section{Figures}


A

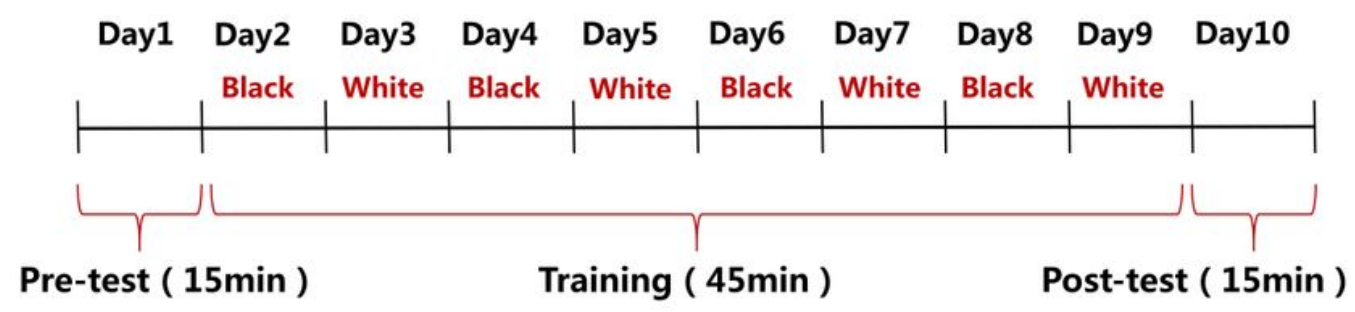

B

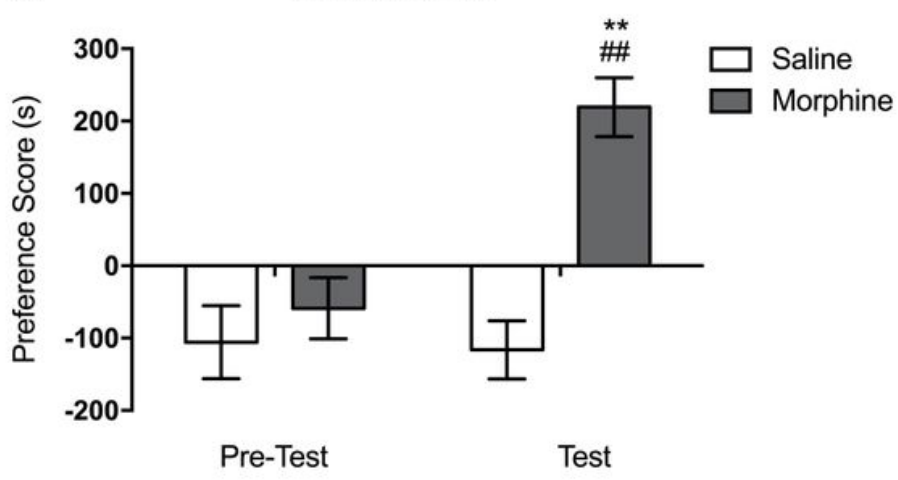

D

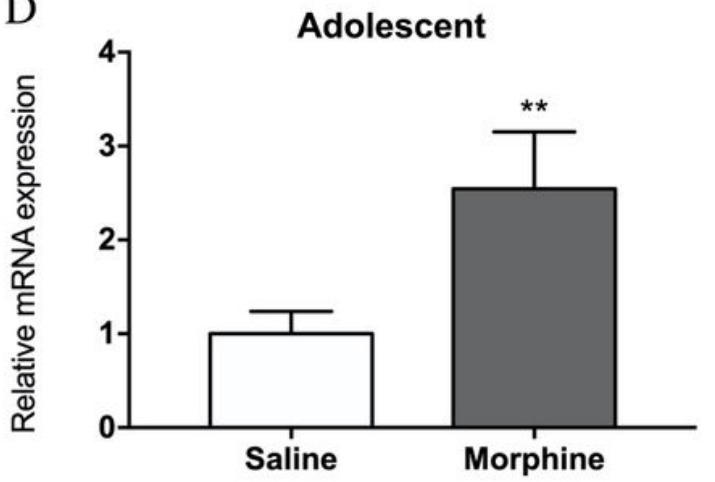

$\mathrm{C}$

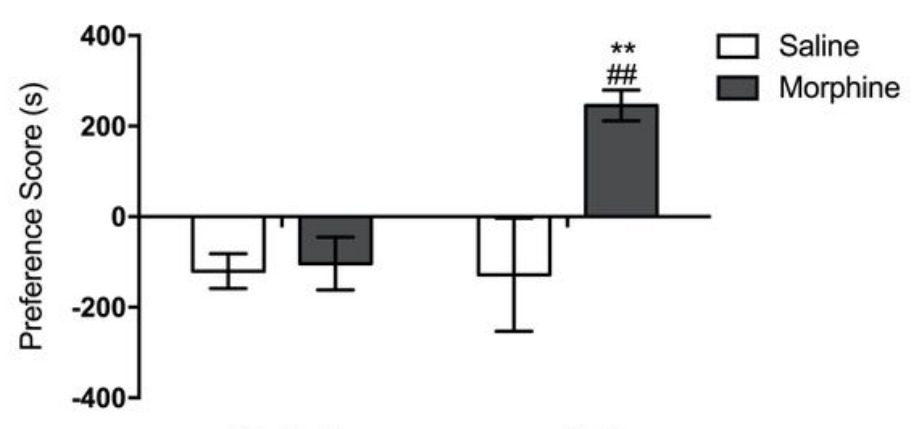

Pre-Test

Test

$\mathrm{E}$

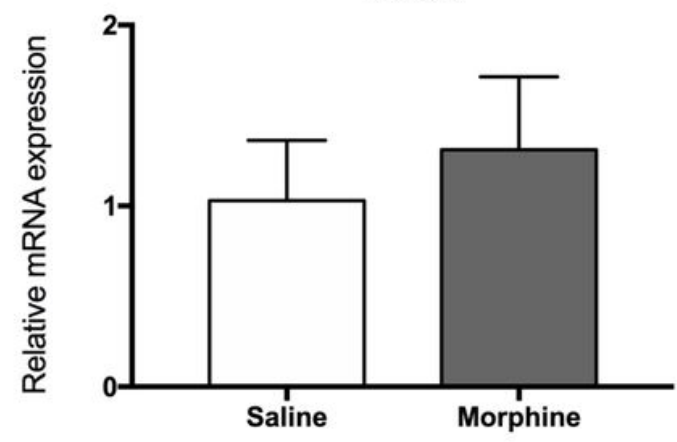

Figure 1

Morphine-induced CPP of mice and increased the expression of p75NTR in the hippocampus of adolescent mice Process of CPP. (A) The schematics of Morphine-induced CPP. (B) (C) Administration of morphine could increase the preference score and induce CPP of both adolescent and adult mice. Repeated-measures of ANOVA was used for the statistical analysis, ${ }^{\#} P<0.05$, compared to saline group; ${ }^{*} P<0.01$, compared to their pre-test. (C) (D) Morphine-induced expression of p75NTR in the hippocampus of adolescent and adult (Student's test was used for the statistical analysis; $* \star P<0.05$, compared to saline group). $\mathrm{N}=6-10$ and all data were presented as the means \pm standard error of the mean. 


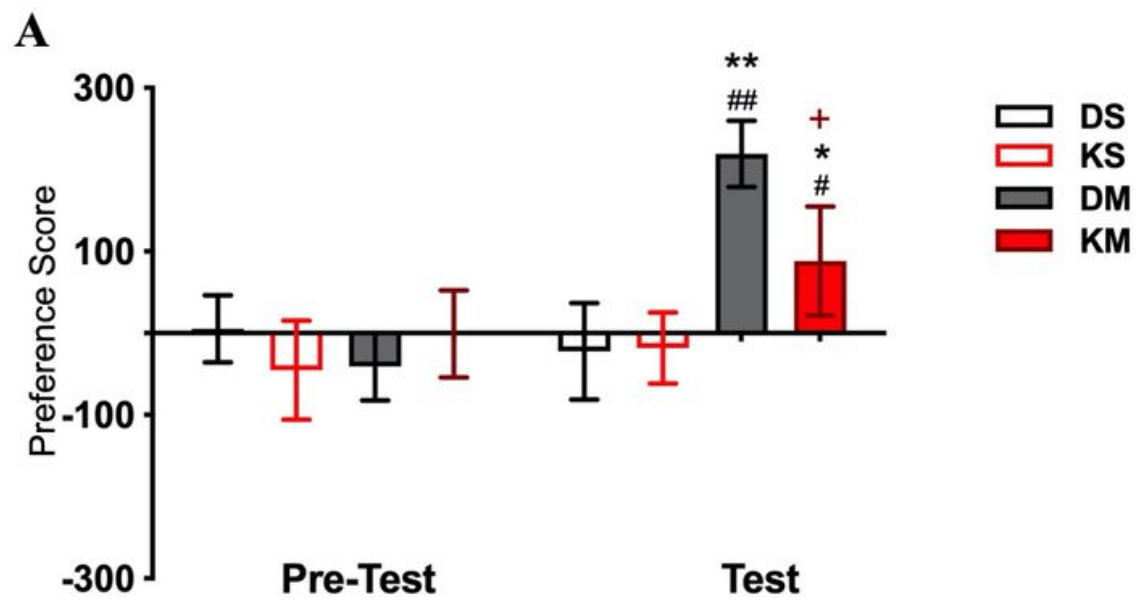

B

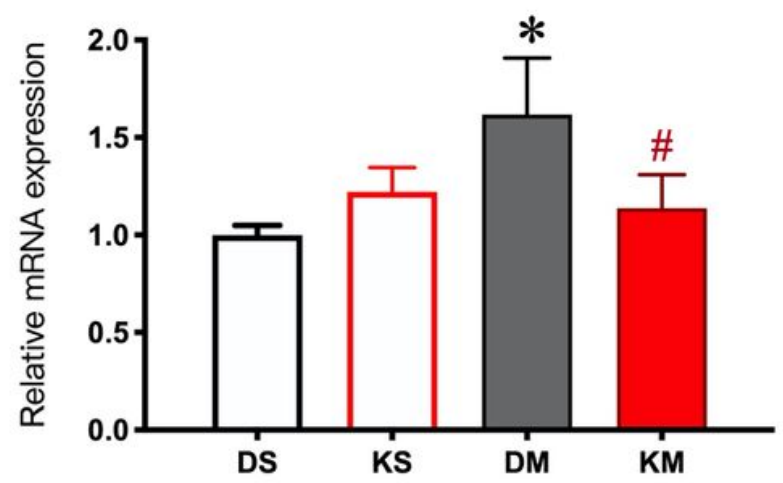

C

CDC42

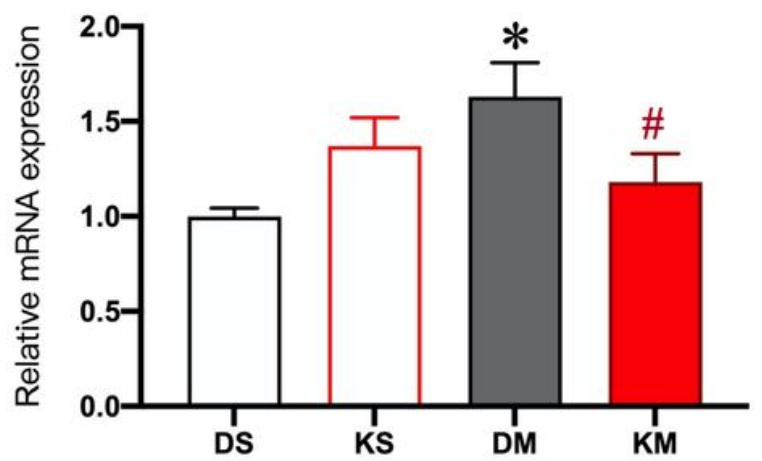

Figure 2

Effects of K252a on morphine-induced CPP and the expression of p75NTR and CDC42 in the hippocampus of adolescent mice. (A) K252 attenuated morphine-induced CPP of adolescent mice. Mixed measured ANOVA was used for the statistical analysis, $* P<0.05, * * P<0.01$, vs. DM and KM group on the pre-test day respectively; $\# P<0.05, \# \# P<0.01, D M$ and $K M$ vs. $D S$ and $K S$ group on the test day respectively; $+P<0.05$, DM vs KM. mRNA expression of p75NTR (B) and CDC42 (C) in the hippocampus were regulated by inhibition of TrkA-p75 complex in response to morphine in adolescent mice. Two-way ANOVA was used for the statistical analysis, ${ }^{*} P<0.05$, DS group compared with DM group; $\#<0.05$, KM group compared with DM group. $\mathrm{N}=6-8$ and all data are presented as the means \pm standard error of the mean. 


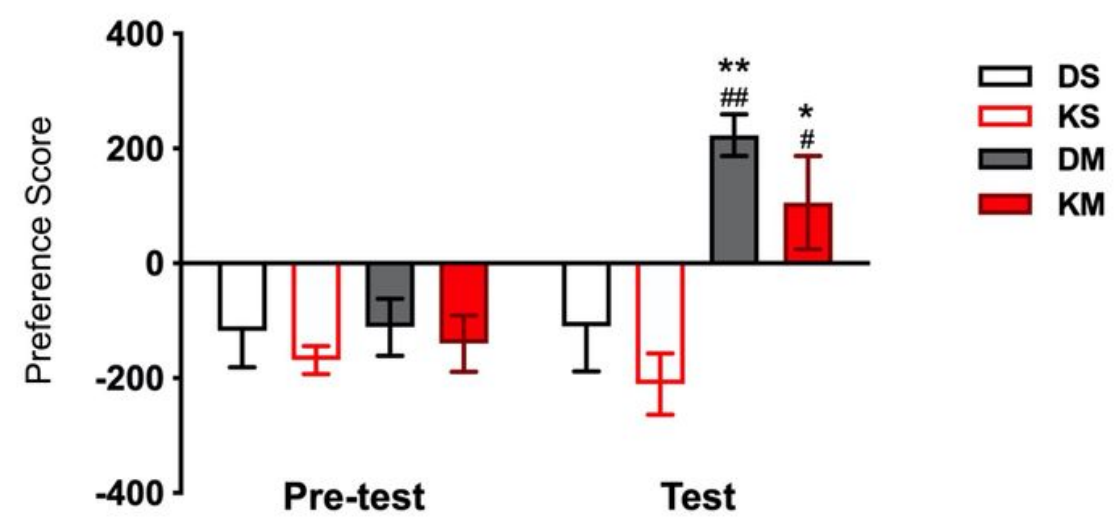

B P75NTR

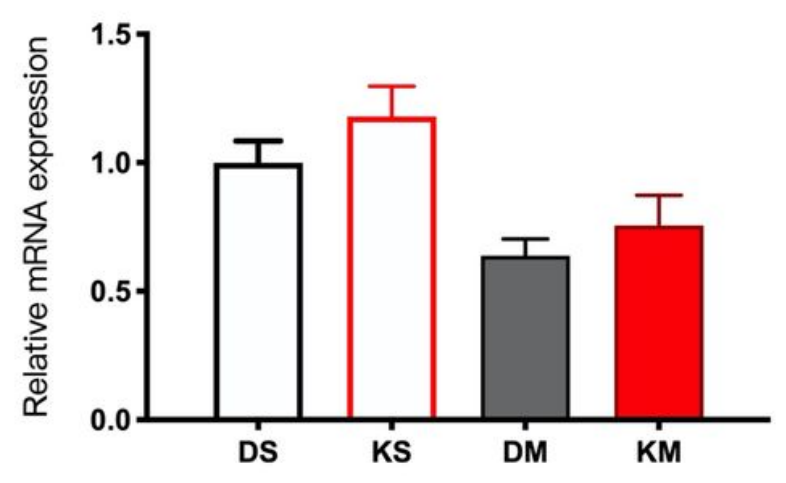

C

CDC42

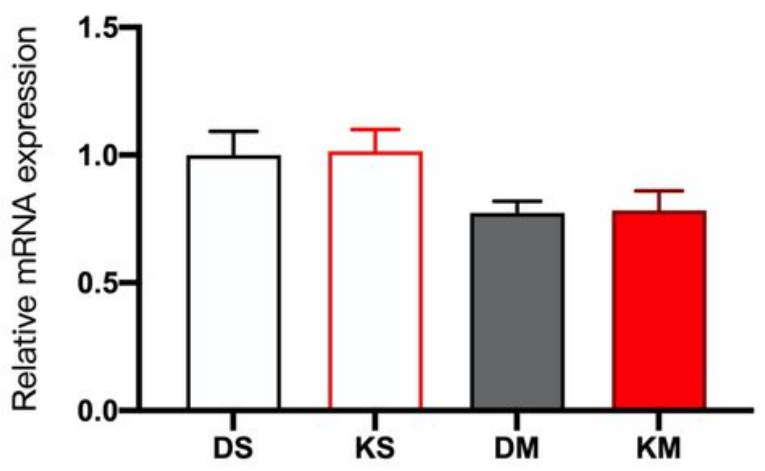

Figure 3

Effects of K252a on morphine-induced CPP and the expression of p75NTR and CDC42 in the hippocampus of adult mice. (A) K252 attenuated morphine-induced CPP of adult mice. Mixed measured ANOVA was used for the statistical analysis, ${ }^{*} P<0.05,{ }^{*} P<0.01$, vs. DM and KM group on the pre-test day respectively; $\# P<0.05, \# \# P<0.01, \mathrm{DM}$ and $\mathrm{KM}$ vs. DS and $\mathrm{KS}$ group on the test day respectively. mRNA expression of p75NTR (B) and CDC42 (C) in the hippocampus were regulated by inhibition of TrkA-p75 complex in response to morphine in adult mice. Two-way ANOVA was used for the statistical analysis. $\mathrm{N}$ $=6-8$ and all data were presented as the means \pm standard error of the mean. 